\title{
Development and implementation of bottom ash crushing system in Submerged Scrapper Conveyor (SSC) for Coal-fired Power Plant
}

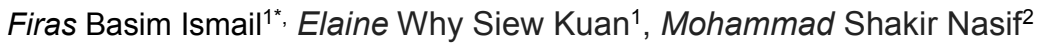 \\ ${ }^{1}$ Power Generation Unit, Institute of Power Engineering (IPE), Universiti Tenaga Nasional, 43000 Kajang, Selangor, Malaysia. \\ ${ }^{2}$ Mechanical Engineering Department, Universiti Teknologi Petronas, 32610 Tronoh, Malaysia.
}

\begin{abstract}
The existence of Submerged Scrapper Conveyor (SSC) in coal-fired power plant is to handle the byproduct of bottom ash. However, soot-blowing will be performed sometimes, in order to remove slag formed at the boiler furnace wall. Thence, this lead to a sudden loading of large amount of slags and bottom ash at SSC after soot-blowing, causing SSC conveying system to jam and conveying chain breakage. In this paper, a new SSC design with additional crushing system is proposed. By implementing the new design proposed, it is expected to improve the overall current performances, and to reduce the trip issue of SSC in coal-fired power plant. The new 3D model of SSC is designed, and stress-strain simulation of the model is analysed by using software of PTC Creo Parametric. Final cost and safety factor analysis of model is made to prove its validation.
\end{abstract}

\section{Introduction and background}

The Submerged Scrapper Conveyor (SSC) is known as to convey and remove the by-product of combusted pulverized coal, bottom ash and slag. It is normally installed at the bottom of boiler. The SSC conveyor drag chain consists of flights, which are located between two parallel length of chain that scrape along the lower surface of the water impounded trough. Further discharge of the bottom ash is transported by belt conveyor, from SSC to ash silo or ash ponds [1]. The conveyor is submerged in water trough below the boiler ash reject hopper. Water contain inside the conveyor box quenches hot bottom ash which falls from the boiler. The fallen bottom ash is then dewatered, as it being scrapped up the inclined section [2].

During the incomplete combustion of pulverized coal at boiler furnace wall, the process will cause accumulation of ash residue on boiler furnace wall surface. Hence, the layers of ash residue formed may seriously inhibit heat transfer to the steam cycle [3]. Therefore, soot blowing process is required, in order to remove these residues. In this soot blowing process, soot blowers are used by using high pressure steam, which impacts on a residue, and leads to its fracture [4]. In this case, residue removal occurs due to mechanical and thermal stresses, induced in the residue $[5,6]$. The fallen slag will then pass through the ash reject hopper, and then submerged in the water content of SSC [7, 8]. Further ash discharging process after SSC, is settled by belt conveyors to the bottom ash silo, or to the ash pond.

In this paper, it is aimed to enhance the current SSC design by adding extra feature of crushing system, to reduce the falling rate and size of slag into SSC after soot blowing process. By doing this, SSC tripping issue can be prevented, and improves its durability. It is also expected that the modification of SSC proposed will contribute to plant performance improvement, by reducing the numbers of unplanned outage on SSC. The project discussed in this paper will focus on PTC Creo Software for designing and stress-strain analysis simulation.

\section{Methodology}

In order to design a SSC with new additional crushing system, methodology of five phases are required. The phases are: Studies of problem root cause phase, SSC 3D model designing phase, auxiliaries and material selection for design phase, Simulation analysis phase, and model analysis phase

\subsection{Studies of problem root cause}

Before designing a new implementation of crushing system to the present SSC, it is important to have a review on slag formation and soot blowing process at boiler furnace wall. The important properties of both bottom ash and boiler slag are studied, and listed in Table 1.

\footnotetext{
* Corresponding author: Firas@uniten.edu.my
} 
Table 1. Physical properties of bottom ash \& boiler slag [9].

\begin{tabular}{|c|c|c|}
\hline Property & Bottom Ash & Boiler Slag \\
\hline Specific Gravity & $2.1-2.7$ & $2.3-2.9$ \\
\hline Dry Unit Weight & $\begin{array}{c}720-1600 \mathrm{~kg} / \mathrm{m}^{3} \\
\left(45-100 \mathrm{lb} / \mathrm{ft}^{3}\right)\end{array}$ & $\begin{array}{c}960-1440 \\
\mathrm{~kg} / \mathrm{m}^{3} \\
\left(60-90 \mathrm{lb} / \mathrm{ft}^{3}\right)\end{array}$ \\
\hline $\begin{array}{c}38-42^{\circ} \\
\text { Shear Strength } \\
\text { (Friction Angle) }\end{array}$ & $\begin{array}{c}32-42^{\circ} \\
(<9.5 \mathrm{~mm}\end{array}$ & $\begin{array}{c}36-46^{\circ} \\
(<9.5 \mathrm{~mm} \mathrm{size})\end{array}$ \\
\hline $\begin{array}{c}\text { Maximum Dry } \\
\text { Density } \\
\mathrm{kg} / \mathrm{m}^{3}\left(\mathrm{lb} / \mathrm{ft}^{3}\right)\end{array}$ & $\begin{array}{c}1210-1620 \\
(75-100)\end{array}$ & $\begin{array}{c}1330-1650 \\
(82-102)\end{array}$ \\
\hline
\end{tabular}

The properties provided are used in solving for feed rate of crusher by

$$
Q=\pi 60 D W \omega L \rho \beta
$$

where $Q$ is feed rate of crusher $(\mathrm{t} / \mathrm{hr}), D$ is diameter of roller $(\mathrm{m}), W$ is width of roller $(\mathrm{m}), \omega$ is roller speed (rpm), $L$ is gap between two rollers $(\mathrm{m})$, and $\rho \beta$ is the bulk density of material $\left(\mathrm{t} / \mathrm{m}^{3}\right)[10]$.

\subsection{D model design}

Firstly, the desired output size of the crushed slag load is set, referring to the calculation of crusher distance, Nip angle formula by

$$
\cos \theta=\frac{(R+L)}{(R+d)}
$$

where $\theta$ is the nip angle $\left(^{\circ}\right), R$ is the radius of roll crusher $(\mathrm{m}), L$ is the gap between two rollers $(\mathrm{m})$, and $d$ is the input material size $(\mathrm{m})$ [10]. The optimum nip angle is set to be $35^{\circ}$ as constant variable, and expected output size of the slag infeed is to range between $2 \mathrm{~mm}$ to $3 \mathrm{~mm}$.

Next, the dimension (diameter) of input shaft at the driving motor and the driving pulley is calculated, using the DEGoodman criterion by

$$
d_{i n}=\left(\frac{16 n}{\pi}\left\{\frac{1}{s_{e}}\left[4\left(K_{f} M_{a}\right)^{2}+3\left(K_{f s} T_{a}\right)^{2}\right]^{1 / 2}+\frac{1}{s_{u t}}\left[4\left(K_{f} M_{m}\right)^{2}+3\left(K_{f} T_{m}\right)^{2}\right]^{1 / 2}\right\}\right)^{1 / 3}
$$

where $d_{\text {in }}$ is the input shaft diameter, $\mathrm{n}$ is the safety factor which is set to be $2.5, S_{e}$ is the endurance limit at the critical location of a machine part in the geometry and condition of use, $S_{u t}$ is the ultimate tensile stress of the shaft material, $K_{f}$ and $K_{f s}$ are the fatigue stress-concentration factors for bending and torsion of shaft, $M_{a}$ and $M_{m}$ are the alternating and midrange bending moments, and $T_{a}$ and $T_{m}$ are the alternating and midrange torques [10].

3D model drawing is done by using software of PTC Creo Parametric. The model dimension unit used in software drawing is set to be millimetre ( $\mathrm{mm}$ ), and it is drawn in scale 1:1 according to general dimension. The SSC model parts are firstly drawn in separate individual, and then followed by model assembly. The drawing of SSC model only focused on the crushing system, instead of the conveying system inside.

\subsection{Auxiliaries and material selection for design}

The material for each parts of the SSC model are selected, based on current existing crushing system technology. The material selected for each SSC individual parts, are assigned to the model drawn, by referring to the material dictionary in PTC Creo Parametric.

The suitable crusher duty motor for the new SSC model crushing system developed is selected after the designing process. The rated output power ( $\mathrm{kW}$ and $\mathrm{hp}$ ) of the motor is chosen according to direct calculation of the crusher power by

$$
\text { Design Hp = Transmitted Hp } x N_{s f}
$$

where $H p$ is horse power, and $N_{s f}$ is service factor. After the rated output power of the motor is determined, the total number of model to operate is selected according to current existing technical data. 


\subsection{Stress-strain simulation}

Once the selected type of material is assigned to the new SSC model, simulation of stress-strain analysis procedure is then carried on. The use of software PTC Creo Parametric is remained for this procedure.

Firstly, the constraint is set at the bottom surface of the SSC model, as a mean of the model is fixed on ground. Then, the estimated value of slag load is applied perpendicularly to each unit of the roll crusher in SSC model as shown in Figure 1. The setting of the load is done on the roll crushers, in order to illustrate the falling process of slag after soot blowing process performed at boiler furnace wall. The stress-strain simulation of full SSC model is first being analyzed, then followed by individual parts. Three types of simulation result are obtained, such as von Mises stress, maximum shear stress, and displacement of parts deformation.

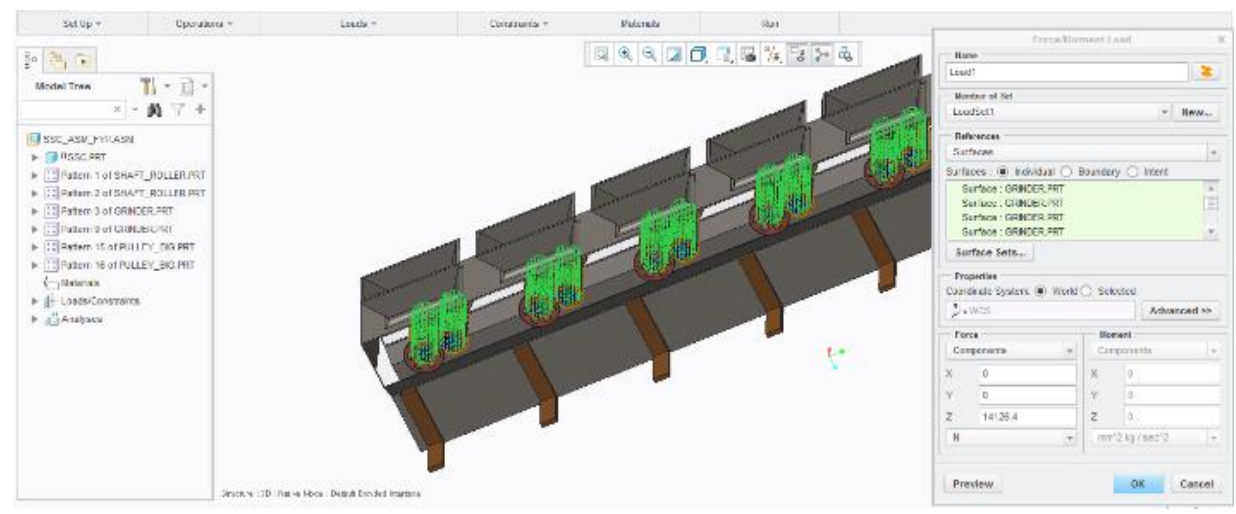

Figure 1. Stress application on model parts for stress strain simulation.

\subsection{Model analysis}

The calculation of the SSC model safety factor is done, right after the results of stress-strain simulation are generated. Only the critical part of the SSC model which has experienced the highest stress and strain, will be analyzed for its safety factor by

$$
S F=\frac{\text { Ultimate Tensile Strength }}{\text { Allowable Stress }}
$$

The optimum safety factor of SSC model is set to be 2 . Any of the safety factor figure calculated less than 2 is considered to be unsafe.

\section{Design overview}

The crusher shown in Figure 2 consists of two sets of running roll crushers, attached with a pulley belt and driving power model at each side respectively. The power model is arranged as such, so that the two roll crushers are able to run at opposite direction facing each other. Hence, crushing action of infeed material will be done. After the crushing process take place at the roll crushers, the slag will be crushed into smaller pieces, and then continue by scrapping and conveying of the SSC below the roll crushers.

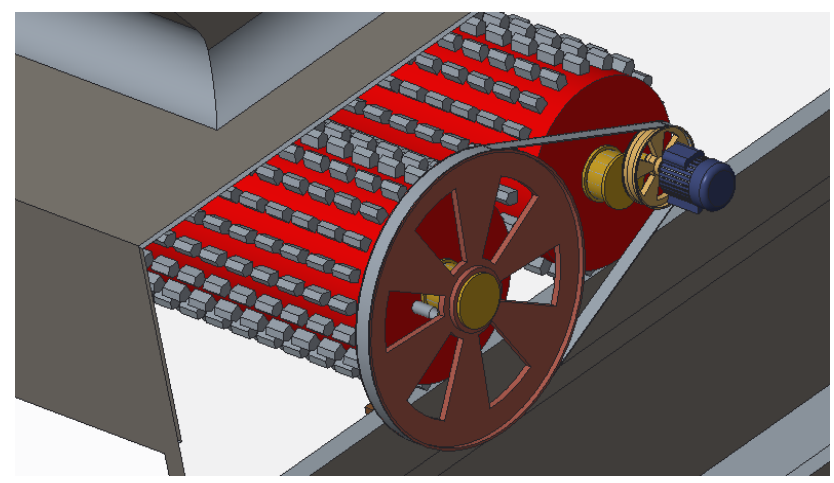

Figure 2. The close-up view of double roller crushing system. 


\section{Stress-strain and deformation displacement analysis}

Based on simulation made, the forces are applied perpendicularly on the surface of each roll crusher, with estimation of $14,126.4 \mathrm{~N}$ (1.6 ton). The simulation results presented in this section includes the criteria of model deflection, von Mises stress, and also maximum shear stress.

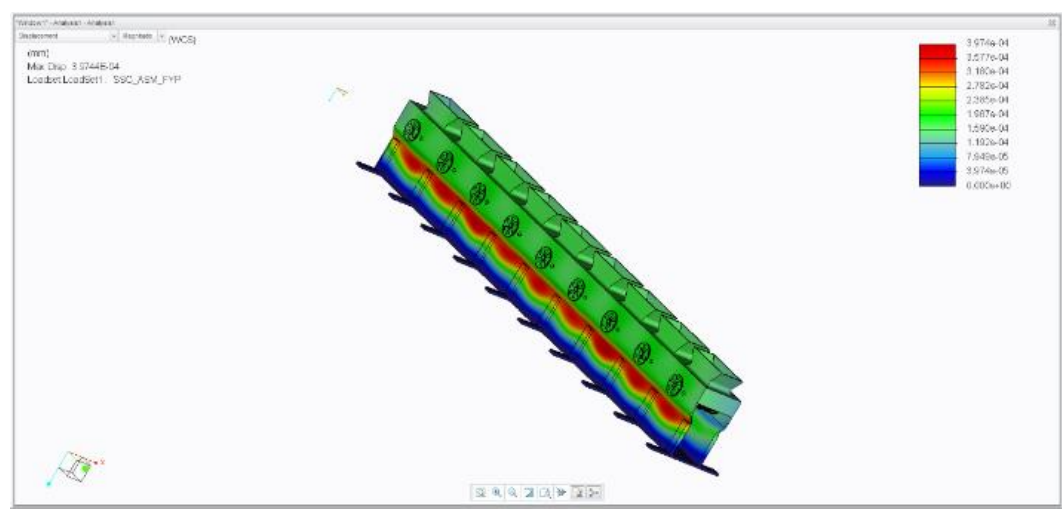

Figure 3. Deflection of SSC model.

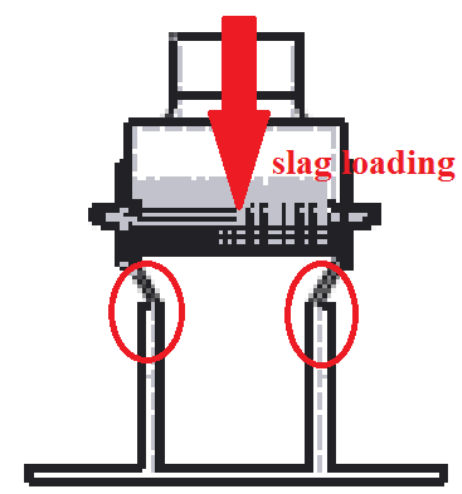

Figure 4. Side view of SSC with slag loading illustration.

The highest deflection of $0.0003974 \mathrm{~mm}$ occurred at SSC model shown in Figure 3 is highlighted in red area. This is due to the geometry design as shown in Figure 4, where loads are exerted in maximum at the bending feature of the design. The support of the model at the highlighted location is said to be the weakest. However, the value of deflection occurred at SSC is considered very low and will not cause failure to the model.

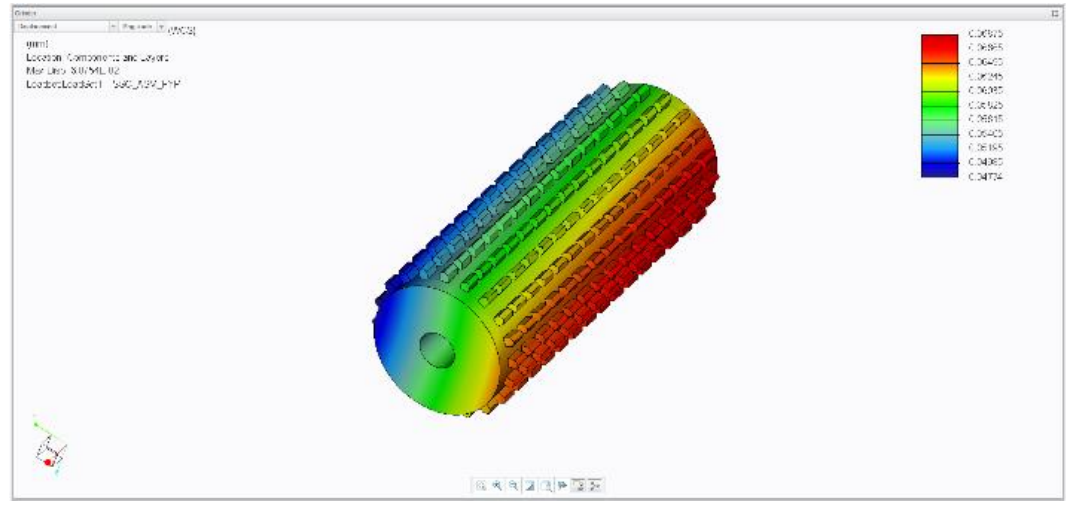

Figure 5. Deflection of roll crusher.

Based on the roll crusher deflection simulation result shown in Figure 5, roll crusher experienced the highest deflection of $0.06875 \mathrm{~mm}$. This is shown in the highlighted red area of the roll crusher, which is facing upward during the simulation process. The high deflection is due to the direct force is applied perpendicularly on the highlighted surface of the roll crusher, with estimation of 14,126.4 N (1.6 ton). Roll crusher experienced the lowest deflection of $0.04774 \mathrm{~mm}$, as represented in the highlighted blue area, which is facing downward during the simulation process. No force is applied on this area of roll crusher. 


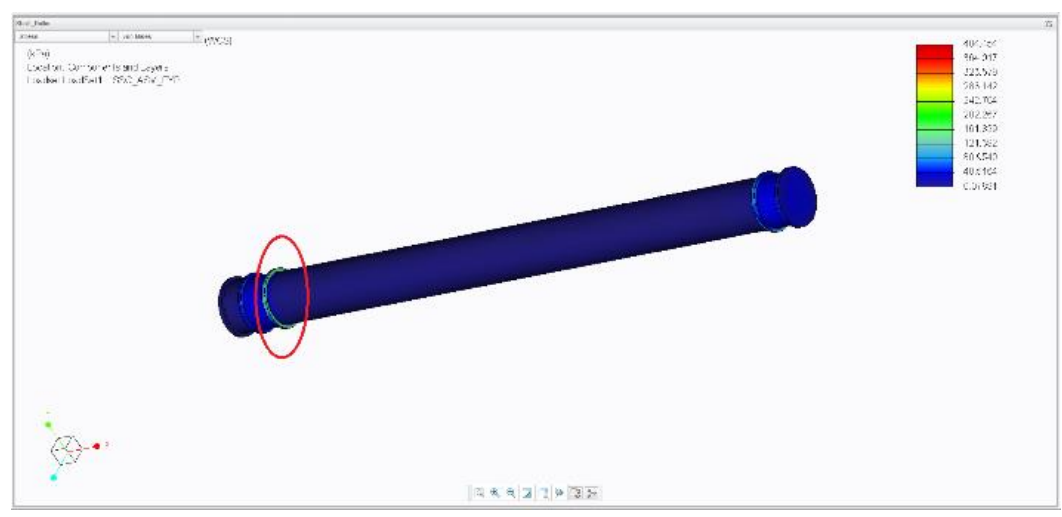

Figure 6. von Mises stress for roll crusher shaft.

A part is said to start yielding when its von Mises stress reaches a critical value known as the yield strength. The von Mises stress is used to predict yielding of part under any loading condition from results of simple uniaxial tensile tests [10]. In this simulation, model part of crusher shaft had experienced the highest value of von Mises stress, which is $404.454 \mathrm{kPa}$ as shown in the highlighted edge in Figure 6. However, by referring to the endurance limit at critical location of crusher shaft and the material ultimate tensile strength, with the value of $262.2 \mathrm{MPa}$ and $690 \mathrm{MPa}$ respectively, the safety factor gained for the roller shaft is to be 2.6316 . The roll crusher shaft experienced the lowest von Mises stress of $0.07891 \mathrm{kPa}$, which is represented by the highlighted blue area of the part.

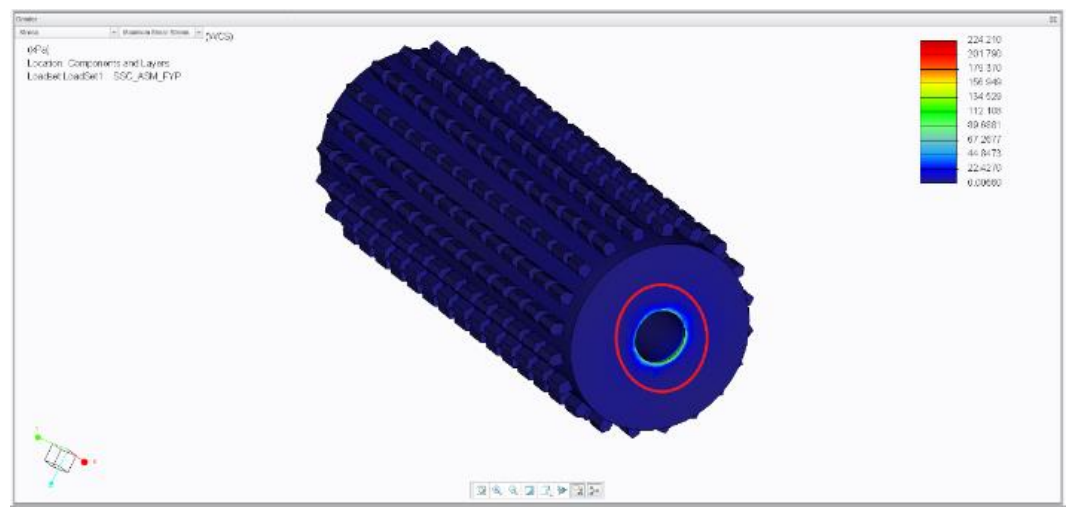

Figure 7. Maximum shear stress for roll crusher.

Shear stress is kwon as a stress state where the stress is parallel to the surface of the material, as opposed to normal stress when the stress is perpendicular to the surface. Shear stress is relevant to the motion of fluids upon surfaces, which result in the generation of shear stress [10]. Based on the roll crusher stress simulation result shown in Figure 7, roll crusher experienced the highest shear stress of $224.210 \mathrm{kPa}$. This phenomenon occurred at the highlighted area of the roll crusher. Roll crusher experienced the lowest shear stress of $0.00660 \mathrm{kPa}$, as represented in the highlighted blue area.

\section{Conclusion and future work}

The input-output relation of the crushing system is highlighted, where the constant outcome of crushed particle in size of $2.313 \mathrm{~mm}$ is achieved. Next, PTC Creo Parametric engineering drawing software plays the main role in completing this project. The software is used for the SSC model 3D drawing, and also to run for stress-strain simulation. Based on the simulation result, roll crusher shaft experienced the highest von Mises stress value of $404.454 \mathrm{kPa}$. Hence, safety factor calculation is done on the roll crusher shaft. The optimum safety factor of SSC model is set to be 2. The final safety factor value of SSC model is calculated to be 2.6316, which means the model is safe to be implemented.

Future works on the new invention of SSC can be made based on the issue faced in coal-fired power plant from time to time. New invention of SSC can be either done by adding extra auxiliary system, or modification on the present technology. Other engineering drawing software such as Solidworks and CATIA are also recommended. By using the recommended software, complete mechanical product including functional tolerances, 3D annotations and kinematics of any designed model can be defined by their modelling tools. Process oriented tools of the recommended software also capture the manufacturing process intent in the early stages of design.

The authors would like to express our gratitude to the power generation unit, institute of power engineering Universiti Tenaga Nasional (UNITEN) TNB Janamanjung and Ministry of Higher Education (MOHE), Malaysia for the opportunity to sponsorship this corresponding research. 


\section{References}

1. Clyde Bergemann Power Group Americas Inc. (2013). Submerged Scraper Coveyor - Wet Bottom Ash Handling [Online].Available:

http://www.cbpg.com/sites/default/files/public\%3A/products_solutions/materials handling/SSC low $\% 20 \mathrm{res.pdf}$

2. B. Michelbrink. "Wet Bin for Collection and Quenching of Ashes from a Pulverized Coal Combustion Chamber." U.S. Patent 3915 105, (Oct. 28, 1975).

3. Zbogar et al. (2008, Nov.). "Shedding of ash deposit.". Progress in Energy and Combustion Science. 38(1), pp. 1-26.

4. D. H. Archer and M. M. Ahmed. "Method for soot blowing automation/optimization in boiler operation." U.S. Patent 4996951 A, (Mar 5, 1991).

5. P. Kittipongpattana and T. Fongsamootr. "Stress Analysis of Water Wall Tubes of a Coal-fired Boiler during Soot Blowing Operation," World Academy of Science. vol. 10, No:3, pp. 451-455, (2016).

6. F. Graube et al. "Optimisation of water-cannon cleaning for deposit removal on water walls inside waste incinerators" Waste Management \& Research. vol. 34, No. 2, pp. 139-147, (2015).

7. Lei Deng et al. "A study on water-quenching waste heat recovery from molten slag of slag-tap boilers". Applied Thermal Engineering. Vol. 108, pp. 538-545, (2016).

8. P. Regucki et al. "Study of thermal-flow processes in ash cooler cooperating with CFB boiler," Perspectives in Science. Vol. 7, pp. 353-356, (March 2016).

9. "User Guidelines for Waste and Byproduct Materials in Pavement Construction," U.S. Department of Federal Transportation, New Jersey, FHWA-RD-97-148, (August, 2016).

10. Budynas and Nisbett, "Design of Mechanical Element," in Shigley's Mechanical Engineering Design, 10th Ed. New York, (2015). 